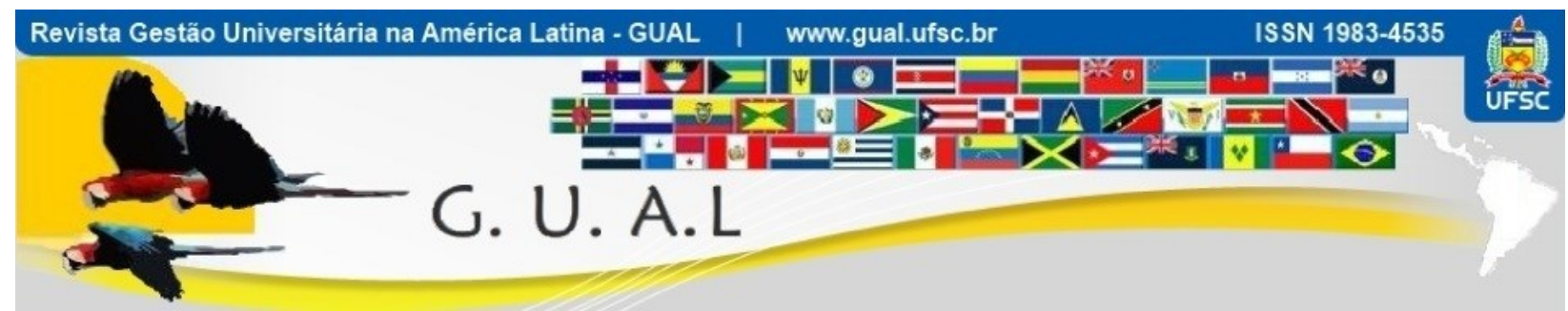

DOI: http://dx.doi.org/10.5007/1983-4535.2016v9n1p37

\title{
MANAGERIALISM NA GESTÃO UNIVERSITÁRIA: IMPLICAÇÕES DO PLANEJAMENTO ESTRATÉGICO SEGUNDO A PERCEPÇÃO DE GESTORES DE UMA UNIVERSIDADE PÚBLICA
}

MANAGERIALISM IN THE UNIVERSITY MANAGEMENT: IMPLICATIONS OF STRATEGIC PLANNING IN THE PERCEPTION OF MANAGERS FROM A PUBLIC UNIVERSITY

Lucilaine Pascuci, Doutora Universidade Federal do Espírito Santo - UFES lucilaine.pascuci@gmail.com

Victor Meyer Junior, Doutor Pontifícia Universidade Católica do Paraná - PUCPR victormeyerjr@gmail.com

Bianca Magioni, Graduada Universidade Federal do Espírito Santo - UFES

bianca-magioni@hotmail.com

Rennan Sena, Graduado Universidade Federal do Espírito Santo - UFES rennan.sena@hotmail.com

Recebido em 28/maio/2014

Aprovado em 26/novembro/2015

Sistema de Avaliação: Double Blind Review

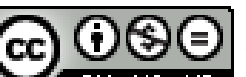

Esta obra está sob uma Licença Creative Commons Atribuição-Uso. 


\title{
MANAGERIALISM NA GESTÃO UNIVERSITÁRIA: IMPLICAÇÕES DO PLANEJAMENTO \\ ESTRATÉGICO SEGUNDO A PERCEPÇÃO DE GESTORES DE UMA UNIVERSIDADE PÚBLICA \\ DOI: http://dx.doi.org/10.5007/1983-4535.2016v9n1p37
}

\section{RESUMO}

A transição do modelo de administração pública burocrático para um modelo gerencial mais efetivo tem exigido uma nova postura das universidades públicas. Em resposta à cobrança por resultados e ao novo cenário, mais exigente e competitivo, tem sido crescente a utilização, na gestão universitária, de abordagens gerenciais oriundas do mercado denominadas de managerialism. Todavia, tais práticas têm se mostrado inadequadas, perdendo muito de sua eficácia por desconsiderarem a complexidade organizacional de universidades, em especial, públicas. O objetivo deste estudo é analisar as contribuições e limitações do Planejamento Estratégico, na percepção dos gestores de uma universidade pública. Dados foram coletados por meio de entrevistas, observação não participante e documentos. Os resultados evidenciam um consenso por parte da gestão e das unidades acadêmicas quanto à necessidade e às contribuições da profissionalização da gestão pública. Indicam, porém, que a ambiguidade das políticas públicas e a excessiva regulamentação do governo federal aliadas à complexidade da organização acadêmica se constituem em sérios limitadores para o sucesso de práticas managerialistas como o planejamento estratégico. As conclusões revelam que a efetividade dessa abordagem gerencial requer adequação da racionalidade implícita no modelo às especificidades das organizações acadêmicas, como condição para que os esforços possam produzir os benefícios esperados.

Palavras-chave: Managerialism. Planejamento estratégico. Gestão Universitária. Universidades Públicas.

\begin{abstract}
The transition from the bureaucratic public administration model to a more effective managerial model requires a new kind of behavior within public universities. As a response to demands of a new more competitive for better performance there is a growing trend among universities of incorporating managerial approaches oriented by the market, and characterized as managerialism. However, such practices have identified as inappropriate losing much of its effectiveness by neglecting the organizational complexity of universities, especially the public ones. The purpose of this study is to analyze the contributions and limitations of the strategic planning incorporated by a public university. The results indicate the existence of a consensus among the central administration and the academic units related to the need for a professionalization of public management. It is also stressed that the ambiguity of public policies and overload of regulations together with the complexity of the academic organization ended up being serious barriers to the success of managerial practices like the strategic planning. The main conclusions reveal that the success of such managerial approach requires the adjustment of the rationality implicit in the model to the specificities of the academic organizations, as a condition by which the efforts can generate the expected benefits.
\end{abstract}

Key Words: Managerialism. Strategic planning. University Management. Public universities. 


\section{MANAGERIALISM NA GESTÃO UNIVERSITÁRIA: IMPLICAÇÕES DO PLANEJAMENTO \\ ESTRATÉGICO SEGUNDO A PERCEPÇÃO DE GESTORES DE UMA UNIVERSIDADE PÚBLICA \\ DOI: http://dx.doi.org/10.5007/1983-4535.2016v9n1p37}

\section{INTRODUÇÃO}

Referindo-se ao contexto universitário brasileiro Claudio de Moura Castro certa vez afirmou que, "dentre públicas e privadas, há dinossauros por todos os lados" (CASTRO, 2003, p. 29). A metáfora "dinossauros", utilizada pelo autor, faz referência à estrutura das instituições de ensino superior (IES) brasileiras que, ao longo do tempo, tem se mostrado cada vez mais burocrática, cara e pouco flexível. $\mathrm{O}$ mesmo se aplica à postura reativa identificada na administração destas organizações, cujas estruturas arcaicas e a falta de resposta aos novos tempos têm sido um dos maiores entraves à efetividade da gestão universitária.

A natureza pública de muitas universidades brasileiras, em especial, exalta uma complexidade de gestão ainda maior. Entre as dificuldades que desafiam seus gestores, se pode mencionar a dependência administrativa pública submetida à copiosa legislação, a falta de autonomia, a rotatividade docente, a isonomia salarial e a pluralidade de agentes e de interesses, na maioria das vezes divergentes (SLEUTJES e OLIVEIRA, 1998; VIERA e VIEIRA, 2004).

Evidencia-se cada vez mais que a universidade pública necessita romper com o atual modelo que a enrijece (VIEIRA e VIEIRA, 2004). Apesar das iniciativas para a transição do modelo de administração pública burocrático para um modelo gerencial e mais efetivo (BRESSER PEREIRA, 1998), as condições de governabilidade de universidades públicas continuam em pauta, especialmente, no que se refere à autonomia, legislação e resultados (MEYER Jr., 2003; VIEIRA e VIEIRA, 2004, por exemplo).

A premência de mudanças estruturais na administração das universidades públicas se mostrou ainda mais evidente a partir da Lei de Diretrizes e Bases da Educação Nacional (LDB) de 1996 e do representativo crescimento do número de instituições e de cursos dela resultante. Neste novo cenário, muito mais exigente e competitivo, tem-se verificado uma preocupação com o aprimoramento da gestão, tanto por parte de IES privadas como públicas. A frenética busca por desempenho - qualitativo e, principalmente, financeiro - tem estimulado a crescente utilização de metodologias gerenciais oriundas do mercado denominadas de managerialism - na gestão universitária (MEYER e MEYER, 2013), na expectativa de torná-la mais condizente com as mudanças contemporâneas. Trata-se de metodologias gerenciais - como planejamento estratégico, por exemplo - criadas para o mercado empresarial e que, cada vez mais, têm sido transferidas à gestão de universidades (MINTZBERG e McHUGH, 1985). 


\section{MANAGERIALISM NA GESTÃO UNIVERSITÁRIA: IMPLICAÇÕES DO PLANEJAMENTO ESTRATÉGICO SEGUNDO A PERCEPÇÃO DE GESTORES DE UMA UNIVERSIDADE PÚBLICA DOI: http://dx.doi.org/10.5007/1983-4535.2016v9n1p37}

Ocorre que a característica simplificada destas práticas tem limitado o alcance de resultados significativos por desconsideram a complexidade organizacional de IES. Autores como Keller (1983), Mintzberg (1994), Birnbaum (2000), Meyer et al. (2012), por exemplo, têm apontado características que colocam as organizações universitárias em um nível de gestão diferenciado daquele das organizações tradicionais. A Teoria das Organizações, influenciada pela economia industrial tem, tradicionalmente, voltado sua atenção às organizações com fins lucrativos, onde predominam modelos e abordagens de natureza essencialmente racional (MINTZBERG, 1994).

Universidades, por sua vez, possuem especificidades que permitem caracterizá-las como organizações complexas (ETZIONI, 1964) e pluralistas (JARZABKOWSKI; FENTON, 2006). Por tratar-se de sistemas frouxamente articulados (WEICK, 1976), a gestão destas organizações também assume forte aspecto político, especialmente, em se tratando de organizações públicas. Portanto, a adoção de abordagens managerialistas têm se mostrado inadequadas às características deste tipo de organização, perdendo assim muito de sua eficácia e funcionalidade (MEYER e MEYER, 2013).

É o caso do planejamento estratégico (PE), sobre o qual tem sido crescente o debate a respeito dos benefícios e limitações, quando adotado em universidades. Em se tratando de universidades americanas, Ginsberg (2011) questiona se os planos estratégicos praticados, de fato podem ser denominados como planos e, principalmente, como estratégicos. Também no Brasil esta discussão há tempos tem se manifestado. Estudiosos como Araújo (1996), Meyer Jr. e Murphy (2003), Vieira e Vieira (2004) e Marra e Melo (2005), por exemplo, ressaltam que a compreensão da cultura e da realidade da universidade é crucial ao sucesso das práticas gerencias adotadas. Isso acontece porque a característica pluralista e complexa de universidades (BIRNBAUM, 2000; JARZABKOWSKI e FENTON, 2006) impacta, significativamente, na tomada e na condução das decisões organizacionais.

Diante do exposto, define-se como objetivo deste estudo o exame das contribuições e limitações do planejamento estratégico adotado em uma universidade pública, segundo a perspectiva dos propositores (alta administração) como também das Unidades Acadêmicas. Este artigo se fundamenta em conceitos de gestão pública, complexidade organizacional e estratégia, com foco em managerialism, para melhor compreender características, resultados alcançados e adequações necessárias às práticas de gestão adotadas no processo decisório de uma universidade pública. 


\section{MANAGERIALISM NA GESTÃO UNIVERSITÁRIA: IMPLICAÇÕES DO PLANEJAMENTO \\ ESTRATÉGICO SEGUNDO A PERCEPÇÃO DE GESTORES DE UMA UNIVERSIDADE PÚBLICA \\ DOI: http://dx.doi.org/10.5007/1983-4535.2016v9n1p37}

Espera-se que os achados deste estudo possam contribuir para o alcance de resultados mais efetivos quando da adoção do PE por parte de organizações universitárias, em especial, as públicas. Em se tratando de organizações não tradicionais estima-se, ainda, que a experiência analisada possa estimular e lançar pistas para a promoção das devidas adequações em modelos gerencialistas, quando aplicados no contexto universitário.

\section{GESTÃO EM ORGANIZAÇÕES PÚBLICAS}

Segundo Ésther (2011), as contribuições do gerencialismo têm sido cada vez mais abordadas como fator de sucesso para as organizações, sobretudo para as privadas. Por outro lado, o mesmo autor destaca que o contexto atual tem exigido o mesmo das organizações públicas, em todas as esferas (municipal, estadual e federal). Ou seja, faz-se necessário uma atuação diferenciada destas organizações, o que implica na adoção de um modelo de gestão também diferenciado (DENHARDT, 2012).

Todavia, ressalta-se a conotação diferenciada que o debate a respeito de eficiência ganha, em se tratando de administração pública. Diferente da eficiência mecânica fria e calculista do setor produtivo, na administração pública este conceito exalta uma conotação mais humana e alinhada a outros critérios presentes na atuação destas últimas (DENHARDT, 2012). Neste sentido, Waldo (1948, p. 202) destaca que, mais do que um valor, a eficiência deve ser "definida em termos do propósito particular a que serve". No caso brasileiro, os desafios que se apresentam para conciliar administração pública e eficiência remetem a velhos debates sobre princípios gerenciais versus burocráticos, e sobre as conhecidas limitações relacionadas à governabilidade (BRESSER PEREIRA, 1998).

A partir da década de 1990, com a Reforma do Estado, observou-se no Brasil algumas iniciativas visando tais mudanças. Uma delas está relacionada ao que, atualmente, tem sido denominado como Nova Gestão Pública (NAP) ou, no Brasil, administração pública gerencial (DENHARDT, 2012). Trata-se de um modelo pós-burocrático que tem base em premissas racionais - análise econômica, accountability, desempenho, medição de produtividade - para a busca de soluções aos problemas governamentais. Nesta perspectiva, a administração pública gerencial admite a condenação do patrimonialismo, assim como a exclusão do modelo burocrático, dada a sua ineficiência (ABRUNCIO, 2007). O interesse público na construção de um governo que funcione melhor e custe menos (DENHARDT, 2012) também foi 


\section{MANAGERIALISM NA GESTÃO UNIVERSITÁRIA: IMPLICAÇÕES DO PLANEJAMENTO \\ ESTRATÉGICO SEGUNDO A PERCEPÇÃO DE GESTORES DE UMA UNIVERSIDADE PÚBLICA \\ DOI: http://dx.doi.org/10.5007/1983-4535.2016v9n1p37}

ressaltado por meio da inclusão do item eficiência na Constituição Federal em 1999 (MELO, SOUZA, CAMPELO e FERASSO, 2012).

No entanto, a adoção indiscriminada na gestão pública de metodologias de gestão embasadas em premissas racionais oriundas de empresas privadas pode ser apontada como uma das principais falhas da NAP (ÉSTER, 2011). Tais transformações podem ser catastróficas à gestão universitária, na medida em que representam a adoção de novos estilos de gestão e valores, um tanto contraditórios ao papel social e contexto organizacional identificado na maioria das universidades públicas.

Embora algumas metodologias de gestão possam se revelar proveitosas, em se tratando de universidades públicas, há alguns cuidados que não podem ser ignorados por administradores públicos. Um deles está relacionado ao desafio que se apresenta mudar uma cultura tão enraizada na gestão das organizações públicas, entre elas, a universidade (MELO et al., 2012). Outro aspecto a ser considerado no aprimoramento da gestão destas organizações, diz respeito ao reconhecimento da complexidade organizacional que lhe é intrínseca (ETZIONI, 1964; MINTZBERG, 1994). Por fim, um último cuidado está relacionado ao entendimento equivocado de que a transposição de técnicas gerencialistas utilizadas por organizações privadas para organizações públicas, apresentará resultados equivalentes.

Diferente das atividades de uma empresa privada, as atividades do governo possuem uma natureza complexa, interconectada e, muitas vezes, ambígua (SAMPAIO; LANIADO, 2009). Além das especificidades de gestão presentes na gestão pública, as universidades públicas ainda possuem a complexidade natural de organizações acadêmicas (ETZIONI, 1964). Ressalta-se, ainda, a dependência administrativa pública, submetida à copiosa legislação e, por conseguinte, a falta de gestão autônoma (VIEIRA e VIEIRA, 2004). Tais elementos dificultam sobremaneira a gestão universitária, bem como a efetividade dos mecanismos adotados nesse processo. Todavia, a ausência de metodologias de gestão apropriadas às suas necessidades, assim como a necessidade de um melhor desempenho organizacional, têm levado muitas universidades a adotarem práticas de gestão oriundas do mercado na sua gestão, nem sempre com resultados satisfatórios. 


\section{MANAGERIALISM NA GESTÃO UNIVERSITÁRIA: IMPLICAÇÕES DO PLANEJAMENTO \\ ESTRATÉGICO SEGUNDO A PERCEPÇÃO DE GESTORES DE UMA UNIVERSIDADE PÚBLICA \\ DOI: http://dx.doi.org/10.5007/1983-4535.2016v9n1p37}

\subsection{MANAGERIALISM NA GESTÃO UNIVERSITÁRIA}

Diante da pressão gerada por um ambiente cada vez mais competitivo, globalizado e tecnológico, tem aumentado a preocupação com a eficiência e eficácia por parte das organizações universitárias (MEYER e MEYER, 2013). Além da preocupação dos gestores universitários há, ainda, a pressão por parte do governo na avaliação do sistema de ensino superior e por parte da própria sociedade, que cobram pela qualidade dos serviços prestados.

Uma vez que não existe uma teoria da administração universitária (KELLER, 1983), a gestão das universidades tem se valido de modelos e paradigmas criados para outros contextos organizacionais (MEYER, 2014). Assim, tornou-se comum a adoção de práticas gerenciais de origem empresarial na gestão universitária, as quais são identificadas como managerialism. Trata-se de um fenômeno amplamente adotado no mundo capitalista, caracterizado pela adoção de metodologias de gestão essencialmente racionais, com foco em controle, eficiência e máxima rentabilidade (QUIGGIN, 2003) que exaltam uma mecanicidade e uma previsibilidade que não se aplicam a muitas organizações (LOCKER e SPENDER, 2011), podendo tornar-se impraticáveis em organizações públicas.

Parker (2002) define managerialism como o desenvolvimento e adoção, por parte das empresas, de abordagens de cunho gerencialista baseadas em princípios racionalistas, cujo objetivo maior é a maximização do controle e da eficiência. Por detrás deste conceito repousa a crença de que há mais similaridades do que diferenças entre as organizações, o que facilitaria a otimização do desempenho organizacional por meio da adoção de práticas de gestão (QUIGGIN, 2003). Nesta perspectiva, a prática do managerialism considera que a administração é uma prática que pode ser transferida a toda e qualquer organização (STACEY, 2010), independente de suas características (MEYER, 2014).

Em acordo com este entendimento, diversas metodologias de gestão oriundas do mercado têm sido absorvidas pela universidade (MINTZBERG; McHUGH, 1985). Pode-se considerar como práticas deste tipo, o Planejamento Estratégico (STEINER, 1979; BORGES; ARAÚJO, 2001), o Orçamento (LEITE et al., 2008; ATKISON et al., 2000), o Sistema ISO (SOUZA; COLLAZIOL, 2006), entre outros.

A adoção do PE por parte de IES, por exemplo, é algo que já acontece há algum tempo, porém, não deixa de ser relativamente novo para o setor (BORGES, ARAÚJO, 2001). Ao observar-se o PE em uma IES, verifica-se um hiato entre o que é planejado e o que é efetivamente realizado, ou seja, uma dicotomia entre a intenção e a ação (MEYER, 2005). 


\section{MANAGERIALISM NA GESTÃO UNIVERSITÁRIA: IMPLICAÇÕES DO PLANEJAMENTO ESTRATÉGICO SEGUNDO A PERCEPÇÃO DE GESTORES DE UMA UNIVERSIDADE PÚBLICA DOI: http://dx.doi.org/10.5007/1983-4535.2016v9n1p37}

Duas razões para a ocorrência deste fato podem ser destacadas. A primeira delas está relacionada à diferença entre as organizações empresariais e as acadêmicas, pois, algumas organizações - como é o caso de universidades, hospitais, instituições públicas, entre outras possuem especificidades as quais podem influenciar na aplicabilidade e efetividade dos resultados decorrentes de práticas, essencialmente, racionais (PASCUCI e MEYER, 2013). A segunda razão diz respeito ao amadorismo gerencial evidenciado em organizações acadêmicas, considerando-se que os cargos de gestão geralmente são ocupados por acadêmicos, os quais, nem sempre são escolhidos por sua experiência nestas atividades (MEYER e MEYER, 2013). Portanto, parece plausível a consideração de McDaniel (2007) ao defender que o fato de práticas de gestão empresariais adotadas em organizações não tradicionais serem menos eficazes do que o esperado se justifica, não pela aplicação incorreta de seus princípios, mas sim, pela desconsideração da natureza complexa destas organizações.

\subsection{A COMPLEXIDADE ORGANIZACIONAL DE UNIVERSIDADES}

Algumas características identificadas em universidades evidenciam a complexidade organizacional já apontada por autores como Etzioni (1964), Orton e Weick (1990) e Jarzabkowski e Fenton (2006), por exemplo. Logo, compreender as mazelas da universidade e buscar soluções para seus problemas exige atenção e análise mais profunda de suas especificidades e de como elas influenciam na gestão, em especial, de universidades públicas.

Ao caracterizar a universidade como organização complexa Etzioni (1964) destaca o seu comportamento imprevisível - resultado de uma miríade de fatores -, que dificulta a compreensão e o gerenciamento destas organizações. A ambiguidade das universidades, já destacada por Baldridge (1983), não se deve apenas ao fato de ofertarem vários e diferentes tipos de serviços à sociedade, mas, porque raramente estas organizações possuem um objetivo único. Isto ocorre uma vez que, em organizações pluralistas, as preferências são obscuras e a multiplicidade de membros e grupos internos persegue, simultaneamente, objetivos diversos, conflitantes e que concorrem entre si (JARZABKOWSKI e FENTON, 2006). Embora legítimas, as múltiplas demandas refletem a contradição de interesses entre stakeholders que detém poder, fato que limita a capacidade dos gestores de promover mudanças voltadas às demandas institucionais.

Em se tratando de gestão, a universidade tem sido caracterizada, ainda, como organização especializada (ETZIONI, 1984), organização profissional (MINTZBERG,1994) e 


\section{MANAGERIALISM NA GESTÃO UNIVERSITÁRIA: IMPLICAÇÕES DO PLANEJAMENTO \\ ESTRATÉGICO SEGUNDO A PERCEPÇÃO DE GESTORES DE UMA UNIVERSIDADE PÚBLICA \\ DOI: http://dx.doi.org/10.5007/1983-4535.2016v9n1p37}

anarquia organizada (COHEN e MARCH, 1974). Organizações especializadas são compostas por grupos distintos onde, pelo menos, $50 \%$ de seus membros são especialistas. A estrutura organizacional, nestes ambientes, passa a ser ao mesmo tempo, burocrática e descentralizada.

Nestas organizações, também denominadas de profissionais (MINTZBERG, 1994), se observa três níveis de tomada de decisão: o julgamento profissional, a ordem administrativa e a escolha coletiva (MINTZBERG, 1994). O julgamento profissional é o mecanismo adotado por profissionais especialistas nas decisões relacionadas a aspectos de natureza profissional. Já as decisões de ordem administrativa restringem-se a questões genéricas, não relacionadas ao trabalho profissional. Desta maneira, é comum que em organizações profissionais - como a universidade, por exemplo - o poder especialista predomine em detrimento do poder burocrático. Há ainda, questões que requerem um processo de tomada de decisão coletivo (BIRNBAUM, 2000). Trata-se das decisões colegiadas, que envolvem uma série de níveis e unidades, as quais interagem num processo coletivo, complexo e político. Logo, paralelo às atividades burocráticas e acadêmicas convive outro tipo de configuração, uma estrutura política com jogos de interesses e conflitos, os quais emergem das interações dos grupos (PETTIGREW, 1973) e impactam diretamente na gestão destas organizações.

A expressão anarquia organizada, adotada por Cohen e March (1974) para representar a universidade, exalta a natureza confusa, ambígua, desconexa e fluída destas organizações. Entendendo as organizações como anarquias organizadas, Cohen, March e Olsen (1972) propuseram o garbage can model, ou, literalmente, modelo da lata de lixo numa analogia a lata de lixo para representar um conjunto de problemas, soluções e preferências de coalizões que ficam misturados, num continuo conflito e disputa por atenção dos detentores do poder de decisão. Como resultado, nestas organizações, é comum haver decisões a procura de problemas, o que exalta o forte aspecto político que estimulou Baldridge (1971) a definir universidades como sendo sistemas políticos.

$\mathrm{O}$ aspecto político, muito presente na gestão de universidades, reforça o conceito de sistema frouxamente articulado definido por Weick (1976). Universidades, como sistemas frouxamente articulados são representados pela heterogeneidade e por múltiplas lógicas de ação e racionalidades, onde a principal forma de regulação é a negociação (WEICK, 1976). Por conseguinte, as decisões que prevalecem nestas organizações representam pequenas 


\section{MANAGERIALISM NA GESTÃO UNIVERSITÁRIA: IMPLICAÇÕES DO PLANEJAMENTO \\ ESTRATÉGICO SEGUNDO A PERCEPÇÃO DE GESTORES DE UMA UNIVERSIDADE PÚBLICA \\ DOI: http://dx.doi.org/10.5007/1983-4535.2016v9n1p37}

vitórias circunstanciais de um grupo sobre o outro, caracterizando um poder compartilhado já que, isoladamente, nenhum dos grupos é suficientemente forte para se impor aos demais.

Portanto, pode-se depreender que administrar a complexidade interna - e externa - da organização acadêmica requer uma abordagem diferente das tradicionais que se pautam em premissas funcionalistas e na otimização de resultados. Tal ambiente caótico, desordenado, descontínuo e imprevisível (STACEY, 1996) exige uma postura mais dinâmica e flexível por parte de seus gestores, mas, também da configuração das metodologias de gestão adotadas.

\section{METODOLOGIA}

Essa pesquisa é de natureza qualitativa e descritiva. $\mathrm{O}$ nível de diagnóstico foi o organizacional e a unidade de análise a percepção da alta administração (professores e administrativos dirigentes) e diretores de unidades acadêmicas quanto à aplicabilidade do Planejamento Estratégico e resultados alcançados na universidade pública em que atuam.

Quanto aos fins trata-se de uma pesquisa descritiva e quanto aos meios, trata-se de um estudo de caso (YIN, 2001). A organização estudada foi uma Universidade Pública Federal, assim denominada para efeitos deste estudo, situada na região Sudeste do País. Em 2013, esta Universidade possuia aproximadamente 22.500 alunos distribuídos em 90 cursos de graduação, 47 cursos de mestrado e 16 cursos de doutorado. O quadro de colaboradores contava com mais de 1650 docentes e, aproximadamente, 2.500 administrativos.

O período estudado foi de 2005 a 2013 por de ter sido a partir de 2005 que a Universidade adotou o PE como metodologia de gestão institucional. A gestão administrativa da Universidade é executada pela Reitoria, órgão executivo máximo da universidade e operacionalizado pelas Pró-Reitorias. Dentre elas, a Pró-Reitoria de Planejamento e Desenvolvimento Institucional, criada em 2005, é responsável pelo PE e pelo Plano de Desenvolvimento Institucional (PDI) onde são definidas prioridades e os rumos de crescimento.

Foram três as principais fontes de coleta de dados: entrevistas, documentos e observação não participante. As entrevistas aconteceram entre fevereiro e março de 2014. Foram 12 os entrevistados, contemplando membros da reitoria, Pró-Reitoria responsável pelo planejamento estratégico (denominados de E1 a E7) e cinco diretores de Unidades Acadêmicas (denominados de E8 a E12). Foram dois os roteiros de entrevistas adotados: um voltado à alta administração e outro voltado às UA, com objetivo de identificar as 


\section{MANAGERIALISM NA GESTÃO UNIVERSITÁRIA: IMPLICAÇÕES DO PLANEJAMENTO \\ ESTRATÉGICO SEGUNDO A PERCEPÇÃO DE GESTORES DE UMA UNIVERSIDADE PÚBLICA \\ DOI: http://dx.doi.org/10.5007/1983-4535.2016v9n1p37}

contribuições e limitações do PE para a instituição, bem como o papel e as responsabilidades da Reitoria e dos Centros nos resultados. As entrevistas foram gravadas para manter a fidedignidade dos dados, com exceção de uma delas, em respeito à solicitação do entrevistado, onde se utilizou diário de campo. A observação não participante aconteceu por meio da participação de um dos pesquisadores em várias reuniões coordenadas pela ProReitoria de Planejamento em 2014, voltadas a análise e revisão do modelo de planejamento adotado. Posteriormente as entrevistas gravadas foram transcritas, assim como os diários de campo, totalizando mais de 140 páginas. Como dados secundários foram utilizados informações disponíveis no site da Universidade, no Planejamento Estratégico (PE) 20052010, no Plano de Desenvolvimento Institucional (PDI) 2010-2014, folders e relatórios.

Os dados primários foram analisados mediante técnica de análise temática, uma das técnicas da análise de conteúdo (BARDIN, 1977). Desta forma, foram elaborados quadros temáticos a respeito das contribuições, limitações e adequações, por parte da alta administração, e por parte dos diretores das UA participantes. Os dados secundários foram analisados mediante análise documental.

\subsection{GESTÃO ESTRATÉGICA NA UNIVERSIDADE PESQUISADA}

Na década de 1980 a Universidade possuia uma Sub-Reitoria de Planejamento e Orçamento, a qual foi extinta devido ao entendimento, por parte de dirigentes da época, de que o PE era por demais complicados para ser desenvolvido na Instituição. Até o início dos anos 2000, várias iniciativas de desenvolver um PE e designar equipe para coordenar as atividades de PE foram propostas por gestões posteriores, também sem sucesso. Ainda assim, algumas práticas foram desenvolvidas informalmente, todavia, sem resultados efetivos dado sua não institucionalização. As descontinuidades de gestão - comum em instituições públicas -, somadas a não profissionalização de gestores para cargos de gestão (MINTZBERG, 1994) e as relações frouxas (WEICK, 1976) entre diferentes áreas autônomas que compartilham o poder neste tipo de instituição, fazia do PE uma intenção de poucos.

A partir do início dos anos 2000 houve uma estruturação organizacional e a PróReitoria de Planejamento passou a funcionar como uma estrutura formal até os dias de hoje. Esta Pró-Reitoria, com o apoio formal da alta administração, elaborou um PE para o horizonte 2005-2010. Foi o primeiro planejamento formal da Universidade, elaborado de forma sistemática com base em premissas do modelo racional de planejamento (MINTZBERG, 


\section{MANAGERIALISM NA GESTÃO UNIVERSITÁRIA: IMPLICAÇÕES DO PLANEJAMENTO \\ ESTRATÉGICO SEGUNDO A PERCEPÇÃO DE GESTORES DE UMA UNIVERSIDADE PÚBLICA \\ DOI: http://dx.doi.org/10.5007/1983-4535.2016v9n1p37}

1994). Este PE conseguiu assumir apenas um caráter simbólico (MEYER, 2005), pois, não chegou a ser reconhecido pelas demais pró-reitorias nem, tampouco, chegar às UA.

Resultados pouco exitosos da primeira experiência estimularam adequações tanto processuais quanto de conteúdo na sua revisão. Uma das medidas adotadas foi integrar o PE ao PDI por acreditar-se que o respaldo legal concentraria esforços em prol dos objetivos institucionais. Assim, o novo PE-PDI, horizonte 2010-2014 teve como foco a integração de Áreas Administrativas e Unidades Acadêmicas.

A elaboração do PE-PDI 2010-2014 contou com a participação de representantes de todas as UA, inclusive representantes da comunidade externa. Apesar dos mais de 130 participantes no workshop de formulação, nem todas as áreas enviaram representantes, com implicações negativas na condução das ações. A fase de formulação foi dividida em duas etapas: na primeira - voltada à definição da Missão, Visão Institucional, diagnose e Matriz SWOT - os participantes foram divididos aleatoriamente em grupos visando dispersar coalizões internas; na segunda etapa os participantes foram agrupados por expertise procurando-se, ainda, desfazer grupos internos de poder. Os cinco grupos da segunda etapa representaram as cinco áreas estratégicas definidas para a IES: Ensino, Pesquisa, Extensão, Assistência e Gestão e, para cada uma delas definiu-se um Objetivo Estratégico, desmembrado em Estratégias e estas, em Projetos Estratégicos.

A fase seguinte buscou validar Projetos e ações deles decorrentes com as áreas efetivamente responsáveis pela sua implementação. Isto ocorreu devido à diversidade de expectativas e a ausência de critérios durante a formulação, que resultou em estratégias e projetos inviáveis e outros que se tornaram obsoletos em pouco tempo. Até o final de 2014, a contratualização das Estratégias e Projetos junto às áreas (administrativas e UA) tinha avançado muito, mas, ainda não estava concluída devido a divergências, descontinuidade de gestores (administrativos e acadêmicos), não institucionalização do PE, entre outros aspectos.

\section{ANÁLISE DOS DADOS}

\subsection{PERCEPÇÕES SOBRE O PLANEJAMENTO E SUAS CONTRIBUIÇÕES}

No Quadro 1 são confrontadas as características e contribuições do PE segundo a literatura relacionada, em relação à percepção da Alta Administração e UA da Universidade. 


\section{MANAGERIALISM NA GESTÃO UNIVERSITÁRIA: IMPLICAÇÕES DO PLANEJAMENTO ESTRATÉGICO SEGUNDO A PERCEPÇÃO DE GESTORES DE UMA UNIVERSIDADE PÚBLICA DOI: http://dx.doi.org/10.5007/1983-4535.2016v9n1p37}

\begin{tabular}{|c|c|c|c|}
\hline \multicolumn{4}{|c|}{ Contribuições do Planejamento Estratégico } \\
\hline \multirow{2}{*}{$\begin{array}{c}\text { O que é proposto na } \\
\text { literatura? }\end{array}$} & \multicolumn{2}{|c|}{ O que é esperado pela Universidade? } & \multirow{2}{*}{$\begin{array}{c}\text { O que } \\
\text { acontece na } \\
\text { prática? }\end{array}$} \\
\hline & Alta Administração & UA & \\
\hline $\begin{array}{l}\text { - Define e diferencia a } \\
\text { organização } \\
\text { - Coordena as } \\
\text { atividades } \\
\text { - Permite integrar } \\
\text { esforços } \\
\text { - Auxilia na busca de } \\
\text { soluções integradas } \\
\text { - Reduz a ambiguidade } \\
\text { e estabelece ordem }\end{array}$ & $\begin{array}{l}\text { - Permitir uma visão } \\
\text { sistêmica da organização } \\
\text { - Definir e controlar } \\
\text { prioridades } \\
\text { - Alinhar metas } \\
\text { - Dividir responsabilidades } \\
\text { - Apoiar o cumprimento de } \\
\text { exigências externas } \\
\text { - Dar retorno à sociedade } \\
\text { - Racionalizar e integrar } \\
\text { esforços } \\
\text { - Otimizar uso dos recursos }\end{array}$ & $\begin{array}{l}\text { - Estabelecer a identidade } \\
\text { institucional } \\
\text { - Representar o caminho } \\
\text { comum a ser seguido } \\
\text { - Definir prioridades } \\
\text { - Aumentar a } \\
\text { previsibilidade no longo } \\
\text { prazo } \\
\text { - Ter visão integrada da } \\
\text { IES } \\
\text { - Permitir a distribuição de } \\
\text { recursos entre UC }\end{array}$ & $\begin{array}{l}\text { - Documento } \\
\text { simbólico, } \\
\text { sem } \\
\text { contribuições } \\
\text { efetivas. }\end{array}$ \\
\hline
\end{tabular}

Quadro 1 Planejamento estratégico: teoria versus prática na Universidade.

Fonte: Pesquisa.

Como se observa no Quadro 1 a percepção dos dois grupos a respeito das contribuições do PE, assumiu perspectivas diferenciadas. Enquanto que a alta administração busca no planejamento um apoio ao cumprimento de metas internas e externas (regulamentações gerais ou específicas para instituições públicas), as UA o veem como possibilidade de desburocratização interna.

Por parte da administração, verificou-se a tendência de se criar uma realidade objetiva e tradicional de PE representado por objetivos, metas, ações e resultados (MINTZBERG, 1994). Apesar da tentativa de conciliar um modelo de planejamento participativo e técnicas de natureza gerencialista os resultados ainda foram incipientes, em termos de legitimidade e efetividade do PE. Mesmo associado ao PDI, com vistas a reforçar a sua legitimidade, as estratégias institucionais ainda pareceram assumir caráter, essencialmente, simbólico. Este entendimento foi justificado por um diretor de UA ao salientar que "não existe nenhum visionário que pense em toda a universidade" (Relato E4), ressaltando a pluralidade de interesses envolvidos.

Embora tenha sido consenso que o PE poderia contribuir para com a gestão institucional e das UA, não foi identificado, por parte dos dois grupos, contribuição efetiva. Dentre os motivos destacaram-se a descontinuidade da gestão, a desvinculação entre planejamento e orçamento, o forte aspecto político, a excessiva burocracia e a ineficácia da estrutura pública. 
4.2 COMPLEXIDADE ORGANIZACIONAL VERSUS LIMITAÇÕES IDENTIFICADAS NA ADOÇÃO DO PE

Dentre as categorias de complexidade organizacional identificadas, algumas demonstraram ter implicações mais significativas na prática do planejamento. Em especial, características do sistema político (BALDRIGDE, 1971; PETTIGREW, 1977), da anarquia organizada (COHEN e MARCH, 1974) e de articulações frouxas (WEICK, 1976), apresentaram implicações mais significativas no desenvolvimento do PE, segundo relatos dos envolvidos.

A autonomia das UA apresentou-se como um dos aspectos mais questionados pela alta administração, por limitar a gestão institucional. Apesar dos esforços para implementar uma gestão moderna, sistemática e integrada, nos moldes da escola Clássica de Planejamento (MINTZBERG, 1994), predominava na universidade uma cultura de "cada um no seu castelo" (E2). De acordo com a alta administração, esta postura é justificada pela autonomia, em especial das UA, as quais privilegiam interesses locais o que inviabiliza, sobremaneira, as iniciativas institucionais. Um representante da alta administração destacou que, "como os centros são autônomos, eles fazem as coisas da forma que eles acham melhor fazer" (E4) fazendo com que as estratégias institucionais deixem de ser prioridade. Um representante da Pró-Reitoria ponta como motivo o fato de as UA terem "facilidade não só para contratar, como para adotar técnicas de gestão diferenciadas” (E3), gerando uma competindo interna que inviabiliza iniciativas integradoras da administração central. Como resultado, "o administrativo e o acadêmico são separados, não existe integração" (E2).

No Quadro 2 são apresentadas as características por meio das quais a complexidade organizacional se apresentou na Universidade pesquisada, segundo categorias analíticas baseadas nos conceitos que orientam este estudo. 


\section{MANAGERIALISM NA GESTÃO UNIVERSITÁRIA: IMPLICAÇÕES DO PLANEJAMENTO ESTRATÉGICO SEGUNDO A PERCEPÇÃO DE GESTORES DE UMA UNIVERSIDADE PÚBLICA DOI: http://dx.doi.org/10.5007/1983-4535.2016v9n1p37}

\begin{tabular}{|c|c|c|}
\hline Característica & $\begin{array}{c}\text { Características de Complexidade } \\
\text { Organizacional } \\
\end{array}$ & Evidências na Universidade \\
\hline $\begin{array}{l}\text { Organização } \\
\text { profissional } \\
\text { (Mintzberg, } \\
\text { 1994) }\end{array}$ & $\begin{array}{l}\text { - Trabalho profissional. } \\
\text { - Autonomia. } \\
\text { - Menor rigor no controle } \\
\text { - Estrutura de poder descentralizada e, por } \\
\text { vezes, fundamentada na especialização. } \\
\text { - Poder burocrático versus especialista }\end{array}$ & $\begin{array}{l}\text { - Autonomia política e administrativa; } \\
\text { gestão autônoma. } \\
\text { - Cultura de "cada um no seu castelo" (E2). } \\
\text { - Flexibilidade organizacional. } \\
\text { - Atores especialistas com capacidade de } \\
\text { intervenção muito grande. }\end{array}$ \\
\hline $\begin{array}{l}\text { Sistema político } \\
\text { (Baldrigde, 1971) }\end{array}$ & $\begin{array}{l}\text { - Modelo de gestão política. } \\
\text { - Racionalidade política. } \\
\text { - Presença de negociação, conflitos, } \\
\text { barganha, coalizão e cooptação. } \\
\text { - Poder compartilhado. }\end{array}$ & $\begin{array}{l}\text { - Diversidade e pluralidade de interesses. } \\
\text { - Busca pelo consenso; plenária. } \\
\text { - Negociação, pactuação. } \\
\text { - "Política quase que partidária" (E1). }\end{array}$ \\
\hline $\begin{array}{l}\text { Sistema } \\
\text { frouxamente } \\
\text { articulado } \\
\text { (Weick, 1976) }\end{array}$ & $\begin{array}{l}\text { - Sistema descentralizado e, ao mesmo } \\
\text { tempo co-dependente. } \\
\text { - Pouco controle burocrático formalizado. } \\
\text { - Unidades semiautônomas de decisão. } \\
\text { - Autonomia profissional. } \\
\text { - Heterogeneidade e múltiplas lógicas de } \\
\text { ação e racionalidade. } \\
\text { - Negociação como forma de regulação } \\
\text { principal. }\end{array}$ & $\begin{array}{l}\text { - Ausência de diálogo entre as diversas } \\
\text { unidades, inclusive científico. } \\
\text { - Grupo heterogêneo e interdependente. } \\
\text { - Ações independentes, sem alinhamento } \\
\text { institucional. } \\
\text { - Decisões dependem de negociação } \\
\text { - Dicotomia entre Administrativo e } \\
\text { Acadêmico. }\end{array}$ \\
\hline $\begin{array}{l}\text { Anarquia } \\
\text { organizada } \\
\text { (Cohen e March, } \\
\text { 1974) }\end{array}$ & $\begin{array}{l}\text { - Natureza confusa, ambígua, desconexa e } \\
\text { fluida. } \\
\text { - Preferências não claras. } \\
\text { - Tecnologia confusa. } \\
\text { - Participação fluída. } \\
\text { - Inexistência de coordenação entre } \\
\text { partes. }\end{array}$ & $\begin{array}{l}\text { - Descontinuidade política } \\
\text { administrativa. } \\
\text { - Extrema dificuldade para formalizar } \\
\text { sistemas de avaliação; } \\
\text { - Monitoramento informal. } \\
\text { - O PE "é vendido" [E11] à cada novo } \\
\text { gestor como produto que compõe } \\
\text { propostas de novos gestores. } \\
\text { - Mudança de comportamento "de fora } \\
\text { para dentro" [E3]. }\end{array}$ \\
\hline $\begin{array}{l}\text { Sistema } \\
\text { complexo } \\
\text { (Etzioni, 1964) }\end{array}$ & $\begin{array}{l}\text { - Atuação em ambiente caótico, } \\
\text { desordenado, descontínuo e imprevisível. } \\
\text { - Evolução depende de auto-organização. }\end{array}$ & $\begin{array}{l}\text { - Depois que o PE fica pronto nota-se que } \\
\text { as coisas se encaminham. }\end{array}$ \\
\hline
\end{tabular}

Quadro 2 Evidências da Complexidade Organizacional na Gestão Estratégica da Universidade. Fonte: Pesquisa.

A relação frouxa identificada entre Administração Central e UA foi outro limitador identificado na implementação do PE na Universidade. Para a alta administração, a multiplicidade de expectativas e interesses (BALDRIDGE, 1971) impacta negativamente no planejamento, na medida em que alimenta a formação de coalizões. O relato de um dos entrevistados corrobora com esta constatação ao afirmar que, em se tratando de reitoria e UA, os "critérios são divergentes, as visões são divergentes, [...] os objetivos diferentes" (E6). Para driblar as divergências internas (PETTIGREW, 1973) a solução encontrada pela Pró-Reitoria foi tentar "trabalhar com o consenso" (E1), assumindo um modelo participativo. Verificou-se, 


\section{MANAGERIALISM NA GESTÃO UNIVERSITÁRIA: IMPLICAÇÕES DO PLANEJAMENTO \\ ESTRATÉGICO SEGUNDO A PERCEPÇÃO DE GESTORES DE UMA UNIVERSIDADE PÚBLICA \\ DOI: http://dx.doi.org/10.5007/1983-4535.2016v9n1p37}

todavia, que mesmo um modelo participativo pode apresentar limitações numa organização pluralista como a universidade, especialmente, quando pública. A adoção do modelo participativo visava "minimizar resistências" (Relato E2), mas, o mesmo entrevistado reconheceu as limitações do modelo participativo ao constatar que "não houve uma participação crítica, só interesses individuais" (Relato E2).

A característica profissional da organização universitária, destacada por Mintzberg (1994), também foi evidenciada nas dificuldades da IES em implantar o PE. De Acordo com um entrevistado, "você lida com atores com uma capacidade de intervenção muito grande [...] que tem uma formação muito elevada" (E3). Além de ser "um grupo muito heterogêneo, [...] com muitas vontades e desejos diferentes" (E5), a natureza pública da universidade apresenta um desafio adicional por tratar-se de profissionais especialistas, autônomos e, ainda, com garantia de estabilidade, como já destacado por Vieira e Vieira (2004).

Portanto, pode-se compreender que a característica essencialmente política do $\mathrm{PE}$ destacada por Pettigrew (1973) assume uma dimensão exponencial em organizações universitárias, em especial, nas públicas. Apesar do processo participativo e da busca pelo consenso na Universidade estudada, a transformação de intenções em ações só teve início a partir de um intenso processo de "interação, negociação e pactuação" (E2) entre as áreas, etapa esta não prevista no modelo formal. A partir desta necessidade, a Universidade estabeleceu nova etapa no processo de formulação, denominada de contratualização, com objetivo de validar as estratégias definidas inicialmente, pois, segundo um entrevistado, "a pactuação permite que você estabeleça metas que são realmente factíveis" (E3).

A pactuação representou uma forma de estabelecer co-responsabilidade e enfrentar o forte aspecto político. Este comportamento é apontado como um dos grandes desafios de gestores universitários, como destacou um entrevistado, ao afirmar que "[...] você tem o cara do Centro que não apoiou o reitor, por exemplo, aí ele pode ser inimigo e falar 'não vou fazer' ou "vou boicotar o processo"” (E2). Alguns comportamentos internos demonstraram, segundo relatos, tratar-se de "uma política quase que partidária" (E4). O aspecto político já destacado na organização acadêmica por Baldridge (1983), por exemplo, é exaltado, segundo um entrevistado, pela "descontinuidade política e administrativa” (Relato E1) característica de IES públicas.

Os aspectos decorrentes da complexidade organizacional representam, em grande parte, as limitações identificadas na adoção do PE na Universidade. Um resumo das 
limitações é apresentado no Quadro 3 confrontando a perspectiva da alta administração e também das UA.

\begin{tabular}{|c|c|c|}
\hline Representantes da... & Limitações identificadas no PE... & $\begin{array}{c}\text { Evidências } \\
\text { de... }\end{array}$ \\
\hline \multirow{5}{*}{ Alta administração } & $\begin{array}{l}\text { - Resistência às metodologias de gestão oriundas do } \\
\text { mercado } \\
\text { - Falta de autonomia para definição de metas } \\
\text { - Dissociação entre Administração e UA }\end{array}$ & $\begin{array}{l}\text { Organização } \\
\text { profissional }\end{array}$ \\
\hline & $\begin{array}{l}\text { - Forte viés político inviabiliza ações e torna o processo } \\
\text { moroso } \\
\text { - Apoio de docentes "Depende da boa vontade" (E6) } \\
\text { - Interferência do modelo de decisão colegiada } \\
\text { - Atores internos e externos que interferem no processo } \\
\text { decisório }\end{array}$ & $\begin{array}{l}\text { Sistema } \\
\text { político }\end{array}$ \\
\hline & $\begin{array}{l}\text { - Poder de intervenção das UA } \\
\text { - Autonomia das UA } \\
\text { - PE deve ser "vendido" às unidades } \\
\text { - Recursos financeiros como mecanismo de barganha }\end{array}$ & $\begin{array}{l}\text { Sistema } \\
\text { frouxamente } \\
\text { articulado }\end{array}$ \\
\hline & $\begin{array}{l}\text { - Ambigüidade dos objetivos institucionais } \\
\text { - A ótica ultrapassada de eficácia por parte da gestão } \\
\text { pública que gera pesados mecanismos de controle } \\
\text { - Questões jurídicas contraditórias que regem o setor } \\
\text { público. } \\
\text { - O planejamento vem a reboque do orçamento }\left(\mathrm{PPA}^{\mathrm{i}}\right) \text {. }\end{array}$ & $\begin{array}{l}\text { Anarquia } \\
\text { organizada }\end{array}$ \\
\hline & - Dificuldade de controle e avaliação & $\begin{array}{l}\text { Sistema } \\
\text { complexo }\end{array}$ \\
\hline \multirow{5}{*}{ Unidades Acadêmicas } & $\begin{array}{l}\text { - Multiplicidade de interesses e objetivos na UA } \\
\text { - Perda de conexão de Departamentos com objetivos } \\
\text { institucionais } \\
\text { - Excesso de burocracia e normas. }\end{array}$ & $\begin{array}{l}\text { Organização } \\
\text { profissional }\end{array}$ \\
\hline & $\begin{array}{l}\text { - Membros das UA criam mini-sistemas políticos } \\
\text { - Plano é simbólico e ações dependem de articulações } \\
\text { políticas } \\
\text { - Influência negativa de diferenças políticas no PE } \\
\text { - Característica política da distribuição de recursos }\end{array}$ & $\begin{array}{l}\text { Sistema } \\
\text { político }\end{array}$ \\
\hline & $\begin{array}{l}\text { - PE visa atender "grupos" } \\
\text { - Morosidade devido às relações de dependência }\end{array}$ & $\begin{array}{l}\text { Sistema } \\
\text { frouxamente } \\
\text { articulado }\end{array}$ \\
\hline & $\begin{array}{l}\text { - Ambigüidade de objetivos institucionais } \\
\text { - Dissociação entre PE e orçamento } \\
\text { - "Sectarismo Departamental" (E6) } \\
\text { - Dicotomia entre intenção e ação } \\
\text { - Predomínio ações reativas e corretivas ao invés de } \\
\text { planejamento }\end{array}$ & $\begin{array}{l}\text { Anarquia } \\
\text { organizada }\end{array}$ \\
\hline & - Descrédito por parte dos professores quanto ao PE & $\begin{array}{l}\text { Sistema } \\
\text { complexo }\end{array}$ \\
\hline
\end{tabular}

Quadro 3 Limitações do PE versus Complexidade Organizacional.

Fonte: Elaborado pelos autores.

Verifica-se no Quadro 3 que as percepções dos grupos acerca das limitações do planejamento, como praticado na Universidade, são muito similares. Dois aspectos 


\section{MANAGERIALISM NA GESTÃO UNIVERSITÁRIA: IMPLICAÇÕES DO PLANEJAMENTO \\ ESTRATÉGICO SEGUNDO A PERCEPÇÃO DE GESTORES DE UMA UNIVERSIDADE PÚBLICA \\ DOI: http://dx.doi.org/10.5007/1983-4535.2016v9n1p37}

decorrentes da complexidade organizacional são destacados por ambos os grupos: o sistema político e anarquia organizada.

Também as limitações da natureza pública da Universidade foram percebidas como negativas na gestão estratégica destas organizações. Aspectos relacionados à regulamentação e ótica de eficácia da gestão pública, a partir de pesados instrumentos de controle e o hiato entre planejamento e orçamento também se constituem grandes limitadores apontados.

\section{DISCUSSÃO}

Pareceu ser consenso por parte da alta administração e das UA que o PE é uma metodologia de gestão que pode contribuir para a profissionalização da gestão pública. Porém, os desafios que se apresentam para que a adoção desta metodologia de gestão apresente resultados mais efetivos são muitos e, não necessariamente, dependem apenas da gestão das universidades públicas, mas, adentram outras instâncias do setor público.

A dissociação entre planejamento e orçamento, por exemplo, é destacado pela maioria dos entrevistados como sendo "uma das principais barreiras à institucionalização do planejamento em IES públicas” (E3). Soma-se a isso o fato da universidade pública não possuir um orçamento próprio já que "o planejamento é acarreado pelo Plano Plurianual” (E1) que, somado a outros fatores, limita significativamente a autonomia das universidades públicas, como já destacaram Sleutjes e Oliveira (1998). Portanto, a primeira grande limitação encontrada por universidades públicas no uso efetivo do PE contradiz uma de suas premissas básicas que é a integração entre metas e recursos financeiros (MINTZBERG, 1994).

Outro aspecto que não pode ser ignorado diz respeito às especificidades da organização universitária pública (ETZIONI, 1964, por exemplo), assim, como destacou McDaniel (2006) parece equivocado esperar que a replicação de um modelo empresarial permita o alcance de resultados similares em universidades e, se acrescenta aqui, especialmente, nas de natureza pública. Uma das limitações decorrentes da complexidade organizacional identificada na Universidade foi a dificuldade de implementação de uma gestão de longo prazo, nos termos de Ginsberg (2011). A este respeito, um entrevistado afirmou que o alcance de resultados poderia contribuir para aumentar a credibilidade do PE, mas, "em universidades públicas isso é complicado, pois o PE não alcança resultados no curto prazo" (Relato E3). 


\section{MANAGERIALISM NA GESTÃO UNIVERSITÁRIA: IMPLICAÇÕES DO PLANEJAMENTO ESTRATÉGICO SEGUNDO A PERCEPÇÃO DE GESTORES DE UMA UNIVERSIDADE PÚBLICA DOI: http://dx.doi.org/10.5007/1983-4535.2016v9n1p37}

A experiência da IES permitiu constatar a existência de um círculo vicioso exaltado pela complexidade organizacional (MEYER, 2007) onde "o planejamento não funciona devido às características da organização universitária que, por sua vez, passa a acreditar menos no planejamento" (E1). Trata-se da ambigüidade de objetivos (formais e informais) devido aos diferentes grupos que compartilham o poder (WEICK, 1976) os quais dificultam a elaboração de um plano integrado, já que diferentes grupos perseguem objetivos diferenciados. Como resultado, verifica-se uma série de problemas de gestão como, por exemplo, a má utilização dos recursos financeiros que, de acordo com um dos entrevistados acontece porque "como não é planejado, é tudo muito atropelado [...] e depois, para não perder o recurso eles fazem qualquer coisa, compram qualquer coisa, treinam qualquer coisa" (E2). Fazendo referência às ciências da complexidade, apenas a capacidade de autoorganização de organizações complexas, como é o caso da universidade (MEYER, 2014), explica a manutenção da perenidade administrativa, neste contexto ambíguo, caótico e essencialmente político.

Outro fator que demonstrou limitar a capacidade de planejamento está relacionado à ambigüidade decorrente de políticas públicas inerentes às IES. Ou seja, apesar do reconhecimento de que o sistema público e dentro deste, as universidades, necessitam tornarem-se mais efetivas e menos custosas, se verifica também a necessidade de adequações estruturais na máquina governamental (BRESSER-PEREIRA, 1998). A excessiva regulamentação, a desconsideração dos vícios do funcionalismo público e o hiato entre objetivos e os recursos para a sua implementação se constituem em sérios limitadores para o sucesso de práticas managerialistas como o PE.

Os aspectos destacados, entre outros fatores, permitem reconhecer que adequações às metodologias tradicionais de PE tornam-se essenciais em se tratando de sua aplicação em universidades. Como destacou um dos entrevistados "a universidade é uma organização diferente das organizações tradicionais, portanto, qualquer mudança leva muito mais tempo" (E1). Tal entendimento tem estimulado a equipe da pró-reitoria a promover adequações na metodologia a cada nova rodada. Uma das adequações, por exemplo, foi o foco em estratégias que denominaram de "guarda-chuva", que visam orientar e manter a coerência ao designar "o quê fazer", enquanto que o "como fazer" fica a cargo das Áreas e UA.

A observação não participante dos autores permitiu constatar uma resistência interna quanto ao uso de "modismos empresariais" (E8) no contexto universitário. Este entendimento 


\section{MANAGERIALISM NA GESTÃO UNIVERSITÁRIA: IMPLICAÇÕES DO PLANEJAMENTO \\ ESTRATÉGICO SEGUNDO A PERCEPÇÃO DE GESTORES DE UMA UNIVERSIDADE PÚBLICA \\ DOI: http://dx.doi.org/10.5007/1983-4535.2016v9n1p37}

resultou da identificação de um "preconceito por parte da comunidade acadêmica quanto à utilização de metodologias empresariais na gestão da universidade" (E1). Verificou-se um processo de aprendizado, considerando-se a contínua revisão da metodologia de planejamento adotada por parte da Universidade de maneira que o novo PDI - em processo de elaboração já apresenta adequações metodológicas adicionais.

\section{CONSIDERAÇÕES FINAIS}

Esse estudo teve como objetivo verificar, com base nos conceitos de complexidade organizacional e de gestão estratégica, quais as contribuições e limitações da adoção do Planejamento Estratégico em uma universidade pública.

Os principais resultados do estudo permitiram constatar que a complexidade organizacional da universidade apresenta significativas limitações à adoção do PE. Entre elas estão a ausência de cultura de planejamento e avaliação, o forte viés político, os jogos de interesse, a falta de integração entre as áreas administrativas e unidades acadêmicas, a autonomia profissional, o poder compartilhado e a resistência às mudanças. Constatou-se também que a percepção das contribuições do planejamento estimula os gestores acadêmicos a persistirem no uso desta metodologia de gestão. Dentre estas contribuições destacou-se o direcionamento para o futuro e a motivação, decorrentes do PE.

A natureza pública da universidade pesquisada demonstrou impactar diretamente nos resultados de sua gestão. Questões jurídicas que regem o setor público e a atual ótica baseada em eficácia que gera pesados instrumentos de controle se constituem grandes limitadores. Em especial, destaca-se a limitada autonomia e a ausência de um orçamento próprio que acaba engessando a gestão universitária.

Aspectos como os apontados, originais do modelo de gestão público, dentre outros aspectos, dificultam o alcance de resultados efetivos por meio da adoção de metodologias oriundas do mercado, como o PE, em instituições públicas como a universidade. É consenso entre os gestores que a profissionalização da gestão pública é essencial, todavia, há muito que ser aprimorado para permitir resultados efetivos na adoção de tais metodologias de gestão. Enquanto a gestão universitária não possui arcabouço teórico e metodologias próprias de gestão, constata-se que as metodologias oriundas do mercado necessitam ser constantemente adequadas à realidade interna da universidade. Caso contrário, embora possam representar 


\section{MANAGERIALISM NA GESTÃO UNIVERSITÁRIA: IMPLICAÇÕES DO PLANEJAMENTO \\ ESTRATÉGICO SEGUNDO A PERCEPÇÃO DE GESTORES DE UMA UNIVERSIDADE PÚBLICA \\ DOI: http://dx.doi.org/10.5007/1983-4535.2016v9n1p37}

uma gestão moderna, tais metodologias desempenharão um papel muito mais simbólico do que contributivo.

A gestão das características complexas da organização universitária se constitui um grande desafio para os seus gestores. Trata-se de temática relevante que carece de estudos mais sistemáticos e aprofundados no âmbito das IES públicas. Neste particular, sugere-se a realização de estudos de caso envolvendo universidades e outros tipos de IES tendo como foco o exame das práticas estratégicas no âmbito organizacional e, em especial, na área acadêmica. Nestes estudos, uma das atenções poderiam se voltar para a extensão em que essas práticas e seus resultados se derivam de planos estratégicos formalmente estabelecidos ou de iniciativas que emergem em diferentes áreas e níveis organizacionais.

\section{REFERÊNCIAS}

ABRUCIO, F. L. Trajetória recente da gestão pública brasileira: um balanço crítico e a renovação da agenda de reformas. Revista de Administração Pública, v. 41, p. 67-86, 2007.

ARAÚJO, M. A. D. Planejamento estratégico: um instrumento à disposição das universidades? Revista de Administração Pública, Rio de Janeiro, v. 30, n. 4, p. 74-86, jul./ago. 1996.

BALDRIDGE, J.V. Power and conflict in the university. New York: John Wiley \& Sons, 1971.

BARDIN, L. Análise de conteúdo. Lisboa: Edições 70, 1977.

BIRNBAUM, R. Management fads in higher education: where they come from, what they do, why they fail. San Francisco: Jossey-Bass, 2000.

BORGES, D. F.; ARAUJO, M. A. D. Uma experiência de planejamento estratégico em universidade: o caso do Centro de Ciências Sociais Aplicadas da UFRN. Revista de Administração Pública. Rio de Janeiro 35(4):63-76, Jul./Ago. 2001.

BRESSER PEREIRA, L. C. Uma reforma gerencial da administração pública no Brasil. Revista do Serviço Público, Brasília, ano 49, n. 1, jan./mar. 1998.

ARAÚJO, M. A. D. Planejamento estratégico: um instrumento à disposição das universidades?. Revista de Administração Pública, v. 30, n. 4, p. 74-86, jul./ago. 1996.

CASTRO, C. de M. Os dinossauros e as gazelas do ensino superior. In: MEYER JR, V.; MURPHY, J. P. Dinossauros, gazelas e tigres: novas abordagens da Administração Universitária. 2 ed. Florianopolis: Insular, 2003. p. 23-38. 
COHEN M. D.; MARCH J.; OLSEN, J. P.A garbage can model of organizational choice. Administrative Science Quarterly, n.17, p. 1-25, 1972.

COHEN, M. D.; MARCH, J. G. Leadership and ambiguity: the American College President. 2.ed. Boston: Harvard Business School Press, 1974.

DENHARDT, R. B. Teorias da administração pública. São Paulo: Learning, 2012.

ÉSTHER, A. B. As competências gerenciais dos reitores de universidades federais em Minas Gerais: a visão da alta administração. Cadernos EBAPE.BR, v. 9, Edição Especial, p. 648667, jul. 2011.

ETZIONI, A. Organizações modernas. 7. ed. São Paulo: Pioneira, 1984.

GINSBERG, B. The strategic plan: neither strategy nor a plan, but a waste of time. The Chronicle of Higher Education, 17, July, 2011.

JARZABKOWSKI, P.; FENTON, E. Strategizing and organizing in pluralistic contexts. Long Range Planning, v. 39, p. 631-648, 2006.

KELLER, G. Academic strategy. Baltimore: The Johns Hopkins University Press, 1983.

MATTOS, P. L. C. L. Réplica: conservadorismo nas universidades federais - o outro lado da resistência à mudança. Revista de Administração Contemporânea, v. 8, n. 2, p. 201-206, 2004.

MARRA, A. V.; MELO, M. C. de O. L. A prática social de gerentes universitários em uma instituição pública. Revista de Administração Contemporânea, v. 9, n. 3, p. 09-31, 2005.

McDANIEL JR, R. R. Management strategies for complex adaptive systems: sensemaking, learning, and improvisation. Performance Improvement Quartely, v. 20, n. 2, p. 21-42, 2007.

MELO, A. C; SOUZA, D.M.; CAMPELO FILHO, E.G.; FERASSO, M. Gestão pública da UFPI: uma análise do seu Plano de Desenvolvimento Institucional (PDI). Revista Gestão Universitária na América Latina, p. 16-35, ago. 2012.

MEYER, B.; MEYER Jr., V. Managerialism na gestão universitária: uma análise de suas manifestações em uma instituição empresarial. Revista GUAL, v. 6, n. 3, p. 01-20, set. 2013.

MEYER JR., V. Planejamento universitário: ato racional, político ou simbólico: um estudo de universidades brasileiras. Revista Alcance, v. 12, n. 3, p. 373-389, set./dez. 2005.

MEYER JR, V. A escola como organização complexa. In: EYNG, A. M; GISI, M. L. (Org). Políticas e gestão da educação superior: desafios e perspectivas. Injuí: Ed. Unijuí, 2007, p. 231-261.

MEYER JR, V. A prática da administração universitária: contribuições para a teoria. Revista Universidade em Debate. 2(1), p. 12-26, 2014. 
MEYER JR, V.; MURPHY, J. P. Dinossauros, gazelas e tigres: novas abordagens da Administração Universitária. 2 ed. Florianópolis: Insular, 2003.

MINTZBERG, H. The rise and fall of strategic planning. New York: Freeman, 1994.

MINTZBERG, H.; McHUGH, A. Strategy formation in an adhocracy. Administrative Science Quarterly, v. 30, n. 2, p. 160-197, 1985.

PARKER, M. Against management, Cambridge: Polity Press, 2002.

PASCUCI, L.; MEYER JR, V. Estratégia em contextos complexos e pluralísticos. Revista de Administração Contemporânea, v. 17, n. 5, p. 536-555, set./out. 2013.

PETTIGREW, A. The politics of organizational decision making. London: Tavistock, 1973.

SAMPAIO, R. M.; LANIADO, R. N. Uma experiência de mudança da gestão universitária: o percurso ambivalente entre proposições e realizações. Revista de Administração Pública, v. 43, n. 1, p. 151-174, jan./fev. 2009.

SANTOS, L. S.; SERVA, M. A Tensão entre a Racionalidade Substantiva e a Racionalidade Instrumental na Gestão Pública: novos caminhos de um campo de estudo. In: EnANPAD, 2013, Rio de Janeiro. Anais eletrônicos.

SLEUTJES, M. H. S. C.; OLIVEIRA, F. B. A crise e a busca de autonomia nas universidades federais brasileiras. Revista de Administração Pública, v. 32, n. 3, p. 29-46, mai./jun. 1998.

STACEY, R. D. Tools and techniques of leadership and management: meeting the challenge of complexity. London: Routledge, 2012.

VIEIRA, E. F.; VIEIRA, M. M. F. Funcionalidade burocrática nas Universidades Federais: conflito em tempos de mudança. Revista de AdministraçãoContemporânea, v. 8, n. 2, p. 181200, abr./jun. 2004.

WALDO, D. The administrative state. Nova York: Ronald Press, 1948.

WEICK, K. E. Educational organization as loosely coupled systems. Administrative Science Quarterly, n. 21, p. 1-19, 1976.

YIN, R. K. Estudo de caso: planejamento e métodos. 2. ed. - São Paulo: Bookman, 2001. 